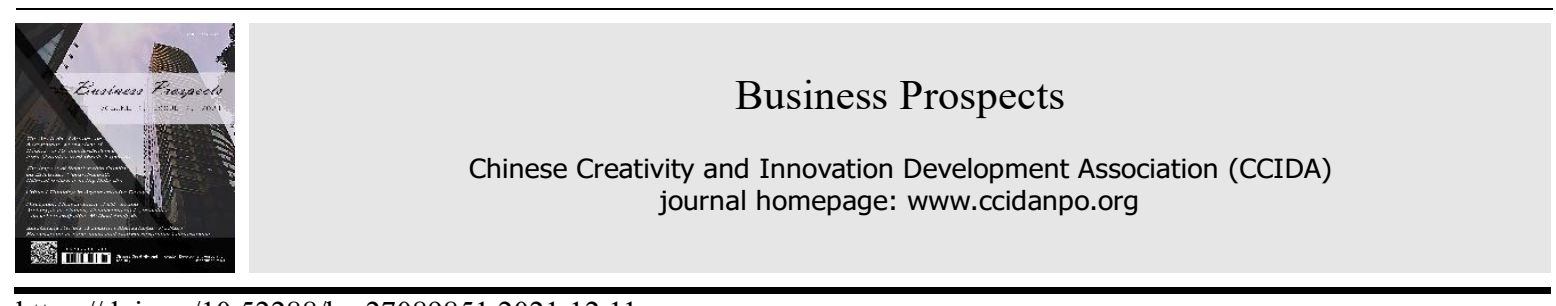

https://doi.org/10.52288/bp.27089851.2021.12.11

\title{
Research on the Development Strategy of Agricultural Products Live E-Commerce
}

\author{
Gong-Jian Zhou ${ }^{1, *}$ \\ ${ }^{1}$ The Xiamen University Tan Kah Kee College \\ *Correspondence: 63223748@qq.com
}

Received: 2021.02.02; Accepted: 2021.09.30; Published: 2021.12.01

\begin{abstract}
With the development of 5G communication technology and mobile Internet technology, live broadcast ecommerce has ushered in a period of high-speed growth. The combination of live broadcast e-commerce and agricultural products has opened a new journey for agricultural e-commerce. This paper traces the origin of agricultural products live e-commerce, combs the development status of agricultural products live e-commerce, deeply discusses the advantages and difficulties of agricultural products live e-commerce, and puts forward some countermeasures and suggestions to promote the healthy development of agricultural products live ecommerce.
\end{abstract}

Keywords: Agricultural Products Live E-Commerce; E-Commerce Platform; Ecosystem; Development; Countermeasures

\section{Foreword}

With the gradual disappearance of traditional e-commerce dividends, traditional agricultural e-commerce has fallen into a downturn, while agricultural live e-commerce has sprung up, showing a good market prospect. The so-called live e-commerce of agricultural products refers to the online interactive communication between the anchor and the audience on agricultural products, so as to promote the audience to buy agricultural products online (Zhao, 2020). Agricultural products live e-commerce is more dependent on the flow of e-commerce platform, with the help of e-commerce platform to carry out live broadcasting. Different from show live broadcasting, game live broadcasting and pan entertainment live broadcasting represented by sports and variety show, agricultural products live broadcasting focuses on the promotion of agricultural products of a certain business or a certain region. Its essence is that the anchor speaks for agricultural products online, and the core is to bring goods.

\section{Development Status of Agricultural Products Live E-Commerce}

Thanks to the upgrading of domestic consumption, the sinking of market, the increasingly mature mobile Internet technology and the increasingly perfect domestic supply chain, after four years of development, agricultural products live e-commerce has become a huge market with a scale of 100 billion. Especially during the 2020 novel coronavirus pneumonia, the direct seeding of agricultural products was thriving in the electricity business, becoming a bright spot in the economy under the epidemic crisis. The e-commerce of live broadcast of agricultural products is very popular. It not only makes head anchors such as Li Jiaqi and Weiya popular, but also attracts more and more entrepreneurs, government officials, entertainment stars and farmers to come into the live broadcast room (Ma, 2020).

According to the data of Pinduoduo platform, from the beginning of the epidemic in 2020 to April 30, more than 150 mayors and county heads of provinces, cities and counties, including Hubei, participated in Pinduoduo's live broadcast of agricultural products, with more than 110 million orders and more than 350 million kg of agricultural products sold (Ma, 2020). On April 6, CCTV news "thank you for your order for Hubei" public action (live broadcast with goods) was launched on CCTV news client, Taobao, Sina Weibo and 
other platforms. CCTV celebrity Zhu Guangquan and super network anchor Li Jiaqi matched the first live broadcast with goods, attracting up to 10 million viewers to watch at the same time, and 12,500 copies of Hubei Jingzhou crayfish were robbed as soon as they were on the shelves. Less than 3 hours after the live broadcast, 40 million yuan of Hubei agricultural products were sold. For a time, "Xiao Zhu Peiqi" has become a hot word on the Internet (Feng and Yin, 2020).

In April 20, 2020, during his inspection in Shaanxi Province, comrade Xi Jinping came to the live broadcast platform of Jinmi village training center in Xiaoling Town, Zhashui County, and praised local specialty Zhashui Auricularia, which became the most popular product of Taobao and other electronic business platforms. The general secretary praised Zhashui Auricularia auricula, which is even more known as "the strongest carrier in history". Agricultural products live e-commerce has become a new model and new normal of agricultural products sales.

\section{Advantages and Difficulties of Agricultural Products Live E-Commerce}

\subsection{Advantage}

\subsubsection{Help to Win the Trust of Consumers}

Under the traditional e-commerce transaction mode, the transparency of the origin, quality and processing circulation of agricultural products is low, and the whole process of agricultural products production and processing can be clearly presented to consumers through live broadcast, so that consumers can distinguish and identify the quality and safety of agricultural products. At the same time, the live e-commerce of agricultural products can make consumers trust more quickly and establish a high degree of trust through the real-time social mode (Ye, 2019).

\subsubsection{Help to Reduce the Market Risk of Agricultural Products}

In the live e-commerce of agricultural products, the anchor directly faces the front line or frontier of the market, and carries out face-to-face real-time two-way communication and feedback with customers through the anchor online, so as to facilitate the collection, analysis and judgment of consumer demand preferences (Wang, 2019). Farmers can change the breeding plan and production and processing plan according to the consumption trend of agricultural products in the live e-commerce, and provide personalized services such as agricultural private customization for consumers, so as to further reduce the market risk of agricultural products and improve the added value of agricultural products ( $\mathrm{Du}, 2018)$.

\subsubsection{Help to Promote the Value Return of High-Quality Agricultural Products}

Most of the agricultural products are non-standard products. Different temperature, humidity, light, soil, breeding environment and processing and storage environment create different quality of agricultural products. Through live broadcast, the sales of agricultural products can be enabled (Feng and Yin, 2020). The anchor can better introduce and recommend the advantages and characteristics of agricultural products to consumers, strengthen the reasons for purchase, share the good things worth having with the audience close to each other, and promote the matching between the price of agricultural products and the value of agricultural products.

\subsubsection{Easy to Use and Copy}

Fashion products such as clothing, shoes and bags, cosmetics and so on have higher requirements for the anchorperson's expression ability, on-the-spot adaptability, professional quality, clothing collocation, beauty design, appearance value and so on (Ma, 2020). The threshold of e-commerce for live broadcast of agricultural products is relatively low. Local flavor and pastoral flavor are its main selling points. On the contrary, the plain and natural nature of farmers become bonus items. With the development of network technology, a smart phone can carry out live broadcast with goods, every farmer can easily do anchor (Ye, 2019).

\subsection{Dilemma}

\subsubsection{Live E-Commerce Supporting Services Lag Behind}

In recent years, the construction of rural transportation infrastructure has been greatly improved, realizing that every village has access to Baiyou Road, and every village has access to highway. However, the current 
situation that logistics stops in villages and towns or administrative villages with convenient transportation has not been broken. For the natural villages with relatively underdeveloped transportation and scattered geographical location, most logistics companies have not extended the distribution scope to the natural villages due to the high cost of collecting and dispatching parts, which undoubtedly hinders the agricultural products from going out of the villages to cities. In addition, $4 \mathrm{G} / 5 \mathrm{G}$ communication technology services and Internet broadband services need to be popularized and improved in rural areas.

\subsubsection{Lack of Talents of Agricultural Products Live E-Commerce}

First, due to the influence of traditional ideas, many farmers still reject the live broadcast on camera and are not willing to try to bring goods in front of the camera. Second, live e-commerce is a new thing, and its normal talent training mechanism has not been effectively formed (Wang, 2019). Third, there are few talents who can take root in rural areas and have long been engaged in the e-commerce industry of live broadcast of agricultural products. It is neither realistic nor economical to rely on social celebrities such as head anchors, artists, hosts and government officials to bring goods for live broadcast of agricultural products for a long time. Occasional Cameo can not solve the fundamental problem ( Du, 2018).

\subsubsection{Weak Awareness of Building the Ultimate Agricultural Products}

Many farmers are used to producing large-scale goods, and they don't pay enough attention to the classification and grading of agricultural products, and there is no shortage of agricultural products. However, the supply of high-quality agricultural products is in short supply, and they lack the initiative of quality control. They can't insist on controlling the number of orders according to their own supply capacity and logistics service capacity (Zhao, 2020). Some farmers are satisfied with the immediate interests, and even produce the shortsighted behavior of selling inferior agricultural products offline rather than online, ignoring the formation of agricultural products network day monument (Du, 2018).

\section{Countermeasures to Promote the Development of Agricultural Products Live E-Commerce}

\subsection{Micro Level}

\subsubsection{Establishing the Sense of Ingenuity}

Farmers should not only have a keen sense of the market and produce marketable agricultural products according to market demand, but also take the initiative to establish a sense of ingenuity, refuse to use inferior, substandard or problematic products for live broadcast sales, and strive to produce and sell high-quality and differentiated agricultural products. In particular, high quality not only refers to good freshness (appearance) and good taste of agricultural products, but also includes high quality and safety level of agricultural products.

\subsubsection{Focus on Packaging Design and Brand Building of Agricultural Products}

First, we should pay attention to the significant role of packaging in enhancing the added value of agricultural products. The packaging of agricultural products should have distinct personality and be able to reflect the differences and professionalism. At the same time, it should also conform to the changes of consumers' ideas, and upgrade to miniaturization, quality, transparency, and environmental protection. In addition, the design of packaging pattern should focus on attracting the attention of consumers, which not only helps to show the functions and advantages of agricultural products, but also helps to convey the image of businesses.

Second, we should pay attention to shaping the brand of agricultural products. In the process of brand building, we should highlight the origin and culture of agricultural products, strengthen the certification of the origin of characteristic agricultural products, actively apply for agricultural products with geographical indications, and give play to the regional advantages of products. We should deeply explore the culture behind the agricultural products, train the story of the products, and enhance the competitiveness of agricultural products with cultural heritage. Regional brand and cultural brand are brand competition tools that are difficult for competitors to follow. 


\subsubsection{Actively Learn and Master Live Marketing Skills}

The first is the skill of live scene selection. In order to deepen the impression of the goods in the hearts of the audience and improve the purchase rate of orders, the live scene should be related to the goods to be brought. For the example of live selling fruits, live scenes can be chosen as the picking site of orchard or fruit planting base. For live selling seafood and other aquatic products, live scenes can be chosen as the fishing port, seaside breeding base or seafood market. For live selling rural handicrafts, live scenes can be chosen as the production site. In short, the live scene must be a persuasive environment for customers.

The second is the collocation skills of live clothing. In the live broadcast, the clothing should be combined with the live broadcast scene, neither exaggerated nor too casual. For example, in the fruit planting base, you can choose to wear the clothing of picking workers; in the fishing port, you can choose to wear the waterproof clothing selling seafood; in the handicraft production site, you can choose to wear the characteristic folk costumes.

Third, the organization skills of live language. First, we can't mechanically explain the product repletely in the live broadcast because the speech expression will be raw and dry and the live broadcast will be boring and disgusting. Anchors should integrate their emotions into the live broadcast and assist with non-verbal communication. They should communicate with customers in a relaxed and pleasant way with humor and sincerity. They should make customers feel that introducing products to them is only based on friendly recommendation, and there is no cheating and forced buying and selling. The relationship between anchor or business and customers is not only a business relationship, but also a deeper friendship. At the same time, we should understand the expression of teenagers, the mainstream group of online consumption, and skillfully use the network catchwords to better adapt to the communication context of the Internet era and directly hit the pain points of consumers.

Finally, we should refine the live style. In order to create the characteristics of live broadcasting, deepen the audience's impression and identity of the anchor, and win customers' continuous attention to live broadcasting, it is necessary to form a unique signboard language.

\subsection{Macro Level}

\subsubsection{Training Local Talents with Live Broadcast and Goods}

It is the key to establish a stable team of local talents for direct seeding of agricultural products. The first is to implant e-commerce live broadcasting courses in e-commerce and other related majors of colleges and universities, and carry out campus live broadcasting practice activities. If possible, colleges and universities can also set up live broadcasting colleges and live broadcasting talent studios, and take various measures to build live broadcasting talent incubation bases. At the same time, we should guide and encourage students, especially graduates from rural areas, to return home for e-commerce live broadcasting and entrepreneurship.

Second, local governments should organize e-commerce live broadcasting enterprises, e-commerce industry associations and colleges and universities to go deep into rural areas to carry out public welfare training of live broadcasting with goods, which can also be implemented in combination with local new vocational farmers training projects. The training form can be either online open class, or on-site demonstration guidance by experts and network celebrities. The training content should cover the basic knowledge of live broadcast, live broadcast operation skills and relevant precautions. For the potential and willing farmers, we can also implement the rural anchor support plan, focus on training a group of live broadcast talents, and play a radiation effect from point to area so that more and more farmers can really become the leading role of live broadcast.

\subsubsection{Improve the New Rural Infrastructure}

First, take the implementation of digital rural development strategy as an opportunity to accelerate the application and popularization of $5 \mathrm{G}$ communication technology in rural areas, steadily promote the full coverage of optical broadband network in rural areas, and provide basic technical support for e-commerce live broadcast of agricultural products.

Second, around the rural poor areas and the main producing areas of fresh agricultural products, we should constantly improve the construction of cold chain logistics facilities, guide logistics enterprises to enter villages and households, set up layout points for natural villages above Designated Size, vigorously promote the construction of rural terminal logistics service network, and open up the "first kilometer" of agricultural 
products entering cities.

\subsubsection{Strictly Control the Quality of Live Agricultural Products}

Under the trend of consumption upgrading, high quality goods are the basis of market competition. Agricultural departments, market supervision departments and other relevant government agencies should formulate and promulgate the quality certification management measures or implementation guidance of live agricultural products as soon as possible, clarify the responsibilities of live platform, business and anchor, and draw the quality red line for live agricultural products from the institutional level. All e-commerce live broadcasting platforms should strengthen self-discipline management, such as establishing strict access standards for live broadcasting of agricultural products, seriously and timely accepting consumer complaints, eliminating the verified agricultural products with quality problems from the live broadcasting list, and ensuring the platform's entry into Japan. In addition, all localities should rely on the local agricultural resources, vigorously cultivate new agricultural business entities, actively introduce leading agricultural enterprises, expand and strengthen the local agricultural advantageous industries and characteristic industries through internal training and external introduction, and on this basis, develop the intensive processing of advantageous and characteristic agricultural products, so as to provide a strong guarantee of high-quality source of goods for the direct broadcast e-commerce of agricultural products.

\subsubsection{Building an Ecosystem of Agricultural Products Live E-Commerce}

All localities should actively guide the direct broadcasting industry to connect with agricultural entity enterprises and large agricultural professional households, organize in-depth exchanges and cooperation, focus on the live e-commerce industry cluster, and build live e-commerce Industrial Park and industrial base. We will build an e-commerce ecosystem integrating e-commerce live broadcasting platform, anchor, content production and production, agricultural product brand, big data operation, packaging design, logistics distribution and talent incubation. For the enterprises in the ecosystem, supporting policies such as office space, tax incentives, talent introduction subsidies and one-stop intermediary services should be provided. For the network red anchor in the ecosystem, high-level talents should be included. By creating a good business environment and talent environment, strong power should be injected into the live e-commerce of agricultural products.

\section{References}

1. Du, Y. W. (2018). New Agricultural E-commerce Mode of “Agricultural Products + Live Broadcast”. Jiangsu Rural Economy, 6: 67-68.

2. Feng, J., \& Yin, Y. (2020). Research on the Current Situation of Short Video Live E-commerce of Agricultural Products. Yangtze River Technology and Economy, 4(11): 177-178.

3. Ma, D. (2020). Research on the Application of Live Broadcasting in the Field of Agricultural Products Sales. Rural Economy and Technology, 15: 153-154.

4. Wang, C. (2019). Research on the Application of Webcast in Rural E-commerce. Mall Modernization, 23: 38-39.

5. Ye, X. M. (2019). New Mode of E-commerce Poverty Alleviation: Live Broadcast + Poverty Alleviation + Industry. Information Construction, 4: 50-53.

6. Zhao, M. S. (2020). Research on the Industrial Development Mode of Rural E-commerce Live Broadcasting. Ecommerce, 5: 13-14.

(Editor: Wenjing Luan) 